\title{
ReLAInEP
}

\section{UM ESTUDO DO SISTEMA DE INFORMAÇÃO LOGÍSTICO DE UMA EMPRESA DO SEGMENTO MERCADOLÓGICO DA REGIÃO NOROESTE DO PARANÁ.}

\author{
Arthur Maffei Angelotti ${ }^{1}$ \\ Dandara Carlessi do Nascimento ${ }^{2}$ \\ João Luiz Cuareli Alécio ${ }^{3}$ \\ Rubya Vieira de Mello Campos ${ }^{4}$
}

\begin{abstract}
RESUMO: O Sistema de Informações Logístico (SIL) dentro das empresas, no contexto competitivo e globalizado atual, torna-se de suma importância para a sobrevivência das mesmas. O presente estudo teve por finalidade identificar o funcionamento de um SIL, bem como seus três subsistemas (sistema de gerenciamento de pedido, sistema de gerenciamento de armazém e sistema de gerenciamento de transporte), em um mercado situado na região noroeste do estado do Paraná. O objetivo principal foi comparar a teoria com os dados levantados durante o estudo. A empresa avaliada tem um SIL, focado nas etapas de controle de estoque e realização de pedidos, porém há falhas na etapa de contato com fornecedores, em que ocorrem atrasos nas entregas dos produtos. Sendo assim, sugeriu-se um sistema computadorizado para registrar os fornecedores e os preços de suas mercadorias, para que os pedidos não atrasem e sejam obtidos pelos melhores preços.
\end{abstract}

Palavras chaves: Gerenciamento de armazéns, Estoques, Transporte.

ABSTRACT: The Logistics Information System (LIS) within companies, in the current competitive and globalized context, it is critical to their survival. This study aimed to identify the operation of a SIL and its three sub-systems (order management system, warehouse management system and transportation management system), in a market located in the northwest of Paraná state. The main objective was to compare the theory with the data collected during the study. The assessed company has a SIL, focused on inventory control phases and applications, but there are flaws in the contact stage with suppliers, it occurs late deliveries of products. Thus, it was suggested a computerized system to record the suppliers and the prices of their goods, so do not delay and order are obtained for the best prices.

Keywords: Warehouse management, Inventory, Transportation.

RESUMEN: El sistema de información para logística (SIL) dentro de las empresas, en el contexto competitivo y globalizado actual, es fundamental para su supervivencia. Este estudio tuvo como objetivo identificar la operación de un SIL y sus tres sub-sistemas (sistema de gestión de pedidos, el sistema de gestión de almacenes y el sistema de gestión de transporte),

\footnotetext{
${ }^{1}$ Universidade Estadual do Paraná, Curitiba/Brasil. arthur_agenlotti@ hotmail.com.

${ }^{2}$ Universidade Estadual do Paraná, Curitiba/Brasil. dandaracarlessi@ outlook.com.

${ }^{3}$ Universidade Estadual do Paraná, Curitiba/Brasil. joãocuareli@ hotmail.com.

${ }^{4}$ Universidade Estadual do Paraná, Curitiba/Brasil. rubyadmc@ @otmail.com.
}

ReLAInEP - Revista Latino-America de Inovação e Engenharia de Produção, Curitiba, PR, Brasil, v. 3, n. 4, p. 223-234, 2015. 


\section{ReLAInEP}

en un mercado situado en el noroeste del estado de Paraná. El objetivo principal fue comparar la teoría con los datos recogidos durante el estudio. La empresa evaluada tiene un SIL, se centró en las fases de control de inventario y aplicaciones, pero hay fallas en la etapa de contacto con los proveedores, que se produce retrasos en las entregas de productos. Por lo tanto, se sugirió un sistema computarizado para registrar los proveedores y los precios de sus productos, por lo que no se demore y el orden se obtiene de los mejores precios.

Palabras clave: gestión de almacenes, inventarios, transporte.

\section{INTRODUÇÃO}

O poder de compra do brasileiro tem aumentado significativamente nos últimos anos, fazendo com que os consumidores se tornem mais exigentes em relação à qualidade, agilidade, flexibilidade e eficiência tanto do produto quanto da compra (OLIVEIRA, 2014), fazendo com que as empresas necessitem aperfeiçoar seus processos de informação, de modo que as informações fluam em toda a cadeia de suprimentos, para assim obterem um melhor gerenciamento de pedidos, armazéns, transporte, banco de dados, e consequentemente atingir a satisfação dos clientes (REIS, 2007).

Desta forma, independente do porte ou setor de atuação da empresa é imprescindível que a mesma tenha um SIL abrangente, para que o fluxo de informações atinja não somente as áreas funcionais da empresa, mas também todos os demais membros do canal de suprimentos (BALLOU, 2006).

Entretanto, cabe ressaltar, que nem todas as informações serão compartilhadas em todo o canal de suprimentos, mas somente as informações necessárias para manter o processo produtivo operando de forma eficiente, pois muitas informações da empresa não podem ser compartilhadas tanto por segurança, quanto para que a empresa consiga se manter competitiva no mercado (BALLOU, 2006).

Portanto, com o intuito de identificar o funcionamento de um SIL, bem como sugerir melhorias conforme a teoria e estabelecer sua influência sobre o nível de satisfação do cliente, foram coletados dados sobre o fluxo de informações em um mercado designado mercado "C" situado na região noroeste do Paraná, no âmbito do sistema de gerenciamento de pedidos, sistema de gerenciamento de armazéns e sistema de gerenciamento de transportes, que são os três subsistemas do SIL (BALLOU 2006).

ReLAInEP - Revista Latino-America de Inovação e Engenharia de Produção, Curitiba, PR, Brasil, v. 3, n. 4, p. 223-234, 2015. 


\section{ReLAInEP}

\section{REVISÃO DE LITERATURA}

Foi embasada em autores que realizaram estudos similares a este, e foram abordados os seguintes subitens: Sistemas de informações logísticos; sistema de gerenciamento de pedidos; sistema de gerenciamento de armazéns; e sistema de gerenciamento de transportes.

\subsection{Sistemas de Informações Logísticas}

O SIL são elos que ligam as atividades logísticas em um processo integrado, combinando hardware e software para medir, controlar e gerenciar as operações logísticas (FLEURY, WANKE, FIGUEIREDO, 2013).

Segundo Nazário (2008), três razões justificam a importância de informações precisas e a tempo para sistemas logísticos eficazes:

a. Os clientes percebem que informações sobre status do pedido, disponibilidade de produtos, programação de entrega e faturas são elementos necessários do serviço total ao cliente;

b. Com a meta de redução do estoque total na cadeia de suprimento, os executivos percebem que a informação pode reduzir de forma eficaz as necessidades de estoque e recursos humanos. Em especial, o planejamento de necessidades que utiliza as informações mais recentes, pode reduzir o estoque, minimizando as incertezas em torno da demanda;

c. A informação aumenta a flexibilidade permitindo identificar (qual, quanto, como, quando e onde) os recursos que podem ser utilizados para que se obtenha vantagem estratégica.

O sistema de informação logísticas possui quatro diferentes níveis funcionais, que são estruturados de forma piramidal (Figura 1), que segundo Fleury, Wanke e Figueiredo (2013), essa estrutura é para mostrar os níveis hierárquicos e o que a atividade do topo depende das demais para ser realizada. São esses níveis:

ReLAInEP - Revista Latino-America de Inovação e Engenharia de Produção, Curitiba, PR, Brasil, v. 3, n. 4, p. 223-234, 2015. 


\section{ReLAInEP}

Figura 1 - Funcionalidade de um sistema de informações logística

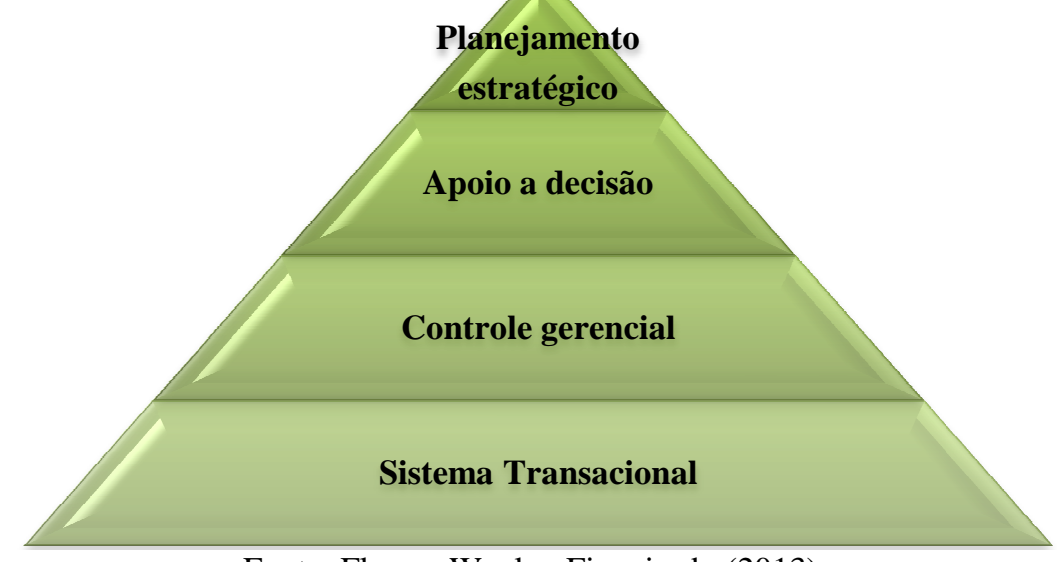

Fonte: Fleury; Wanke; Figueiredo (2013).

a) Sistema transacional: é a base para as operações logísticas, tendo como característica regras formais, comunicação interfuncionais, grande volume de transações e um foco operacional nas atividades cotidianas, com base nele ocorre o ciclo do pedido, esse apresentado na Figura 2.

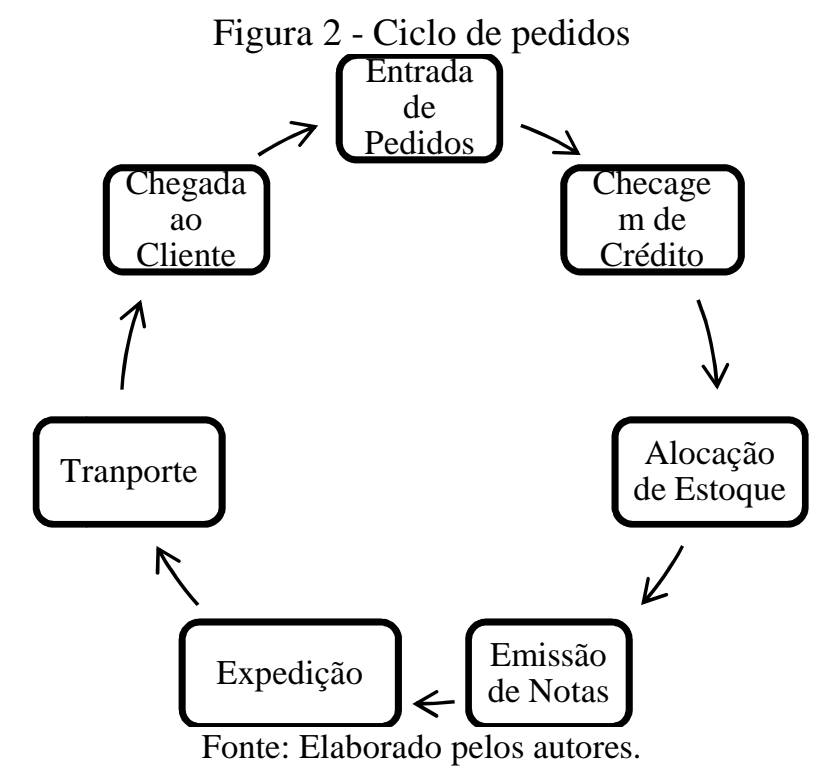

O Ciclo do pedido corresponde a todo o processo e fluxo de informações necessárias para a consolidação de um pedido, incluindo desde o momento em que o cliente efetua o 


\section{ReLAInEP}

pedido até o momento em que paga e recebe o produto seja na loja ou até mesmo em sua residência.

b) Controle gerencial: esse nível permite que se utilizem as informações disponíveis no sistema transacional para o gerenciamento das atividades logísticas, existindo, portanto neste nível uma grande necessidade de indicadores/relatórios de desempenho, sendo os principais: lead time e transit time;

c) Apoio a decisão: a característica desse nível é a utilização de softwares para o apoio das atividades operacionais, táticas e estratégicas;

d) Planejamento estratégico: as informações logísticas servem de apoio para o desenvolvimento e aperfeiçoamento da estratégia logística.

Já para Ballou (2006) o SIL tem por função a busca e coleta de dados para uma melhor manutenção e processamento dos mesmos, para que a empresa possa utiliza-los como auxílio no processo decisório de medidas estratégicas e operacionais, de forma a obter melhores desempenhos das informações logísticas, ou seja, fazendo com que as informações estejam sempre atualizadas e cheguem rapidamente a toda a cadeia de suprimentos.

Desta forma o mesmo autor apresenta três subsistemas principais para o desenvolvimento de um SIL nas empresas que são:
a) sistema de gerenciamento de pedidos;
b) sistema de gerenciamento de armazéns, e;
c) sistema de gerenciamento de transportes.
Os três subsistemas serão brevemente explanados a seguir.

\subsubsection{Sistema de gerenciamento de pedidos}

A frente do sistema de informação logístico tem-se o sistema de gerenciamento de pedidos (SGP), o qual é responsável por toda a comunicação com os demais sistemas de gerenciamento, uma vez que, é no SGP que as primeiras informações da cadeia de suprimentos como um todo são geradas, já que é no mesmo que são geradas as informações de disponibilidade do produto a partir dos estoques e programas de produção, localização do produto, quantidades e prazos para entrega (BALLOU, 2006).

ReLAInEP - Revista Latino-America de Inovação e Engenharia de Produção, Curitiba, PR, Brasil, v. 3, n. 4, p. 223-234, 2015. 


\section{ReLAInEP}

Segundo PeopleSoft (2007), o gerenciamento de pedidos envolve muito mais do que o recebimento de um pedido e seu envio. Atualmente envolve o gerenciamento de pedidos e alocação de estoques.

O sistema de gerenciamento de pedidos também exerce contato direto com os clientes, obtendo suas informações pessoais, condições de crédito dos mesmos, sendo o próprio SGP responsável pela disseminação dos dados dos clientes entre outras informações, para os demais departamentos da empresa (BALLOU, 2006).

\subsubsection{Sistema de gerenciamento de armazéns}

O sistema de gerenciamento de armazéns (SGA) está diretamente interligado com o SGP, uma vez que, para controlar o armazém e realizar as vendas é necessário que o SGA conheça bem os seus clientes e os produtos oferecidos pela empresa (BALLOU, 2006).

Desta forma têm-se cinco elementos principais para o SGA, que são apresentados no Quadro 1.

Quadro 1 - Principais elementos do sistema de gerenciamento de armazéns

\begin{tabular}{|c|l|}
\hline Elemento & \multicolumn{1}{|c|}{ Descrição } \\
\hline Entrada & $\begin{array}{l}\text { Check-in do produto e consequentemente das informações, uma vez que os produtos são } \\
\text { identificados por códigos e quantidades. Dados estes que irão alimentar o sistema de } \\
\text { informação do SGA. }\end{array}$ \\
\hline Estocagem & $\begin{array}{l}\text { Etapa em que os produtos seguem para os armazéns, gerando informações de localização do } \\
\text { produto, para que após a compra do cliente o mesmo possa ser facilmente localizado e retirado } \\
\text { do estoque. }\end{array}$ \\
\hline $\begin{array}{c}\text { Gerenciamento } \\
\text { de estoque }\end{array}$ & $\begin{array}{l}\text { Controle dos níveis de estoque do armazém. Gerando informações sempre que um produto é } \\
\text { retirado para que o gerente de estoque possa informar e alimentar o sistema para que o pedido } \\
\text { de novos lotes seja feito. }\end{array}$ \\
\hline Elemento & \multicolumn{1}{|c|}{ Descrição } \\
\hline $\begin{array}{c}\text { Processamento } \\
\text { de pedidos e } \\
\text { retirada }\end{array}$ & $\begin{array}{l}\text { Planejar a demanda para assim controlar a quantidade de pedidos e a retirada de produtos do } \\
\text { armazém, pois estas são atividades que demandam muita mão-de-obra, e precisam ter suas } \\
\text { informações constantemente atualizadas. }\end{array}$ \\
\hline $\begin{array}{c}\text { Preparação do } \\
\text { embarque }\end{array}$ & $\begin{array}{l}\text { Preparação das quantidades/lotes do produto para embarque de forma a se obter uma } \\
\text { roteirização eficiente, conforme o peso do produto, valor agregado, entre outros. }\end{array}$ \\
\hline
\end{tabular}

\subsubsection{Sistema de gerenciamento de transportes}

O transporte nas empresas é a atividade que tem a maior conta individual de custos logísticos, que varia entre em terço e dois terços do total dos custos logísticos das empresas, desta forma, um bom gerenciamento de transporte pode garantir reduções de custos, um bom

ReLAInEP - Revista Latino-America de Inovação e Engenharia de Produção, Curitiba, PR, Brasil, v. 3, n. 4, p. 223-234, 2015. 


\section{ReLAInEP}

nível de serviços aos clientes, reduções nos tempos de entrega, entre outros benefícios (MARQUES, 2002).

De acordo com Ballou (2006), "O sistema de gerenciamento de transportes (SGT) cuida do transporte da empresa, sendo parte integral do SIL" Já que o SGT também compartilha e faz uso das informações geradas no SGP e SGA. Tendo esta atividade como objetivo principal o suporte ao planejamento e controle de todo e qualquer transporte realizado para a empresa, ou seja, desde o transporte realizado pelos fornecedores, até o transporte realizado pela empresa para a entrega de seu produto final (BALLOU, 2006).

\section{METODOLOGIA}

Utiliza-se como método de abordagem o qualitativo. Sendo a pesquisa classificada, quanto aos meios, como bibliográfica do tipo tradicional e virtual, e quanto aos fins, como descritiva.

O método de abordagem utilizado para identificar os sistemas de informações logísticos utilizados no mercado "C" classifica-se, quanto aos fins, como descritiva e metodológica.

A revisão de literatura focou-se na busca de teses, dissertações, artigos e livros relacionados aos sistemas de informações logísticas utilizadas em empresas, realizados no período de 2005 a 2013, sendo as pesquisas realizadas em sites específicos de pesquisa. As palavras-chave empregadas para tal busca foram: Sistema de informação logístico; Sistema de gerenciamento de pedidos; Sistema de gerenciamento de armazéns; Sistema de gerenciamento de transportes.

A presente pesquisa foi desenvolvida em um mercado situado na região noroeste do Paraná, durante o mês de abril de 2014. O mercado de médio porte conta com 5 funcionários e o dono da empresa que trabalha com a parte financeiro-administrativo. O mercado possui aproximadamente 50 fornecedores e uma clientela fixa mensal de 150 famílias.

ReLAInEP - Revista Latino-America de Inovação e Engenharia de Produção, Curitiba, PR, Brasil, v. 3, n. 4, p. 223-234, 2015. 


\section{REVISÃO DE LITERATURA}

Através das pesquisas realizadas foram encontrados cinco trabalhos relacionados ao sistema de informação logístico de diversas empresas dos mais variados setores, conforme o Quadro 2.

Quadro 2 - Revisão de estudos relacionados ao sistema de informação logístico

\begin{tabular}{|c|c|c|}
\hline Autor & Setor & Objetivos e Resultados do Trabalho \\
\hline $\begin{array}{l}\text { FERREIRA; } \\
\text { ALVES, } \\
(2005)\end{array}$ & $\begin{array}{c}\text { Indústria } \\
\text { alimentícia e } \\
\text { automobilística }\end{array}$ & $\begin{array}{l}\text { Discutem os impactos na logística pela troca eletrônica de informações } \\
\text { entre empresas, principalmente empresas do setor alimentício e } \\
\text { automobilístico, pois estes são uns dos dois setores com mais } \\
\text { concorrência no mercado. Em seus resultados indicam a importância } \\
\text { do uso de EDI (tradicional e via Web) e da Internet na gestão de } \\
\text { estoques, no transporte e no processamento de pedidos, para ganhar } \\
\text { maior eficiência e satisfação do cliente. }\end{array}$ \\
\hline $\begin{array}{l}\text { GUARNIERI } \\
\text { et al. (2006) }\end{array}$ & $\begin{array}{c}\text { Aplicação e } \\
\text { implementação de } \\
\text { conceitos } \\
\text { Bibliográficos }\end{array}$ & $\begin{array}{l}\text { Em seu estudo comparam e discutem a implementação do } \\
\text { gerenciamento de um sistema de logística reversa, integrado ao sistema } \\
\text { de gerenciamento de armazéns, de forma a evitar desperdícios nos } \\
\text { armazéns, ter um fluxo de informações que retornam dos consumidores } \\
\text { para a empresa. Nos resultados explicam quais as funções, benefícios e } \\
\text { fases de implantação dessa integração entre um sistema de } \\
\text { gerenciamento de logística reversa com o sistema de gerenciamento de } \\
\text { armazéns. }\end{array}$ \\
\hline REIS (2007) & $\begin{array}{l}\text { Indústria } \\
\text { alimentícia } \\
\text { (refeições } \\
\text { coletivas) }\end{array}$ & $\begin{array}{l}\text { O estudo teve por objetivo identificar a efetividade e os pontos de } \\
\text { ruptura da cadeia logística de uma empresa do setor de refeições } \\
\text { coletivas. Foram avaliados os indicadores de desempenho logístico da } \\
\text { empresa de forma a investigar os motivos que levavam a paradas no } \\
\text { fornecimento de centros de distribuição da empresa. Ao final do estudo } \\
\text { o autor concluiu que a causa de tais problemas eram os atrasos na } \\
\text { entrega de matéria-prima por parte dos fornecedores e falhas do } \\
\text { operador logístico. }\end{array}$ \\
\hline REGO (2011) & Industrial & $\begin{array}{l}\text { Realizou um estudo na empresa } \mathrm{P} \& \mathrm{G} \text {, com o objetivo de padronização } \\
\text { de processos e rapidez do fluxo de informações nos setores de } \\
\text { execução da produção e expedição do produto acabado. O autor } \\
\text { alcançou como resultados após a aplicação de técnicas e a realização de } \\
\text { estudos, um fluxo de informações mais eficaz em toda cadeia de } \\
\text { suprimentos, reduzindo assim o lead time do produto acabado } \\
\text { principalmente da expedição para o centro de distribuição. }\end{array}$ \\
\hline $\begin{array}{l}\text { BRAIDO } \\
\text { et al. (2012) }\end{array}$ & Varejista & $\begin{array}{l}\text { Os autores propuseram em seu estudo analisar a gestão logística de } \\
\text { uma empresa do setor varejista de autopeças, e sugeriram melhorias } \\
\text { para a empresa conforme os conceitos de tecnologia da informação } \\
\text { aplicados à logística, tais como o controle de estoque computadorizado } \\
\text { para auxiliar os gestores nas tomadas de decisão, e também a } \\
\text { automação nos pontos de venda, no controle financeiro e na divulgação } \\
\text { dos pedidos de compra efetuados. }\end{array}$ \\
\hline
\end{tabular}

A partir da revisão bibliográfica realizada, observou-se que embora existam diversos estudos realizados em diversos setores de atuação das empresas, não há trabalhos com o intuito de levantar dados do sistema de informação logístico baseados nos subsistemas 


\section{ReLAInEP}

definidos por Ballou (2006) em um mercado, como foi o foco deste estudo.

\section{RESULTADOS E DISCUSSÃO}

Os resultados obtidos no estudo de caso realizado no mercado " $C$ " serão apresentados separadamente, conforme as três classificações dos subsistemas do SIL citados por Ballou (2006) na fundamentação teórica.

\subsection{Sistema de gerenciamento de pedidos no mercado "C"}

O sistema de gerenciamento de pedidos no mercado "C" é controlado de maneira qualitativa e quantitativa.

Portanto, para a realização dos pedidos do mercado "C" o gerente baseia-se em demandas anteriores no mesmo período e em dados empíricos e realiza pedidos de mercadorias aos fornecedores semanalmente.

O mercado "C" possui um sistema de informações simples, utilizando apenas computadores e softwares, que, se fazem eficazes e suficientes pelo porte do mesmo.

Quando determinado produto está em falta no estoque, o sistema de identificação por código acusa automaticamente que a quantidade deste produto está em falta ou já está no estoque de segurança, ou seja, que o estoque do produto atingiu uma determinada quantidade anteriormente estabelecida, sendo então disparada uma ordem de pedido desse produto antes do mesmo ficar escasso em estoque.

Em relação aos fornecedores, devido ao mercado ser de médio porte, e não fazer parte de uma rede, os fornecedores estão localizados em diferentes localidades e apresentam preços diferenciados. Para analisar os fornecedores, o mercado "C" possui anotações de atrasos de entrega, assim, cada vez que um fornecedor atrasar uma entrega ele perde confiança e se possível, o mesmo é substituído.

O sistema de gerenciamento de pedidos do mercado " $\mathrm{C}$ " também possui um sistema no qual cadastra todos os dados dos clientes, os quais recebem uma senha para realizar compras a prazo. Assim, quando o mesmo vai até o mercado "C" e solicita que suas compras sejam entregues em domicílio, o próprio sistema, a partir da senha fornecida pelo cliente, imprime

ReLAInEP - Revista Latino-America de Inovação e Engenharia de Produção, Curitiba, PR, Brasil, v. 3, n. 4, p. 223-234, 2015. 


\section{ReLAInEP}

um comprovante com o valor da compra e o endereço em que a mesma deve ser entregue.

\subsection{O sistema de gerenciamento de armazéns no mercado " $\mathrm{C}$ "}

O mercado "C" possui um espaço destinado ao desembarque dos caminhões que chegam com os produtos no decorrer do dia. Após o desembarque os produtos são identificados por códigos e quantidades para manter o controle de estoque e informações. Essa etapa do SGA de acordo com Ballou (2006), é denominada de "entrada ou check-in".

Em seguida os produtos são estocados em um armazém localizado ao lado do mercado. Cada produto possui diferentes necessidades de armazenamento, conforme suas características, sendo assim o armazém é dividido em setores, para que todos os produtos sejam armazenados corretamente.

O gerenciamento de estoques é realizado através de um software. Os produtos são cadastrados um a um, sendo que quando o nível de qualquer produto estiver baixo, o programa avisa, para que então o operador possa comunicar o gerente, que irá realizar pedido de um novo lote de compra.

Como o mercado "C" é de médio porte, algumas mercadorias não são mantidas em armazéns, ou seja, todo o estoque de determinados produtos fica exposto nas gôndolas. O controle destes produtos realizado por meio do SGP, o qual controla os produtos que não passaram pelo check-in através do código utilizado para colocar preço no produto. Entretanto como esses produtos não possuem estoque de segurança, o funcionário responsável pela reposição dos produtos nas gôndolas, fica responsável de informar o SGP quando o nível de estoque do produto está baixo.

\subsection{0 sistema de gerenciamento de transporte no mercado " $C$ "}

O gerenciamento de transporte não é uma atividade muito representativa para a empresa, devido se tratar de um mercado de médio porte. O mercado "C" não possui frota de caminhões para o transporte dos produtos. Os fornecedores realizam o transporte de seus produtos até a empresa, incluindo assim no valor da mercadoria os custos com o transporte.

O mercado realiza entregas para seus clientes em domicílio. Para isso, conta com a

ReLAInEP - Revista Latino-America de Inovação e Engenharia de Produção, Curitiba, PR, Brasil, v. 3, n. 4, p. 223-234, 2015. 


\section{ReLAInEP}

ajuda de um veículo. As compras são armazenadas em caixas de plástico com dimensões de $60 \mathrm{~cm}$ x $40 \mathrm{~cm}$, sendo as mesmas colocadas no veículo para realizar as entregas. Para reduzir os gastos de transporte, uma viagem de entrega é realizada somente quando tiver no mínimo 8 caixas de compra para serem entregues.

As entregas das compras não são cobradas do consumidor por um raio de até $10 \mathrm{~km}$ de distância do mercado. Caso a distância para a entrega seja maior, é cobrado $\mathrm{R} \$ 0,80$ por km rodado.

\section{CONSIDERAÇÕES FINAIS}

Ao término do estudo de caso realizado no mercado "C", constatou-se que o SIL é de suma importância para a sobrevivência das empresas, sendo elas de pequeno, médio ou grande porte. Para ter um bom entendimento do SIL, é necessário à compreensão de seus subsistemas (sistema de gerenciamento de pedidos, sistema de gerenciamento de armazém e sistema de gerenciamento de transporte), pois os mesmos são a base para o desenvolvimento e obtenção de resultados da área de SIL.

Comparando o sistema de gerenciamento de pedidos do mercado "C" com a teoria base utilizada de Ballou (2006), foi possível observar que o mesmo possui um SGP eficiente, já que consegue ter um cadastro e controle dos clientes, passa e recebe informações para os demais setores do mercado e realiza previsões semanalmente mantendo o sistema sempre atualizado do estoque. Entretanto sugere-se ao mercado que crie um sistema computadorizado para registrar os fornecedores e os preços de suas mercadorias, respectivamente, para que os pedidos não atrasem, sejam obtidos pelo melhor preço e os fornecedores não necessitem ser trocados frequentemente.

Já no sistema de gerenciamento de armazéns observou-se que o sistema utilizado é suficiente, porém quando os produtos ficam apenas armazenados em gôndolas as chances de falta de determinado produto aumentam, sendo assim, recomenda-se que todos os produtos, mesmo os comprados em pequenas quantidades, passem pelo check-in, para que assim possam ser devidamente controlados.

Quanto ao sistema de gerenciamento de transportes, conclui-se que pelo porte do mercado o sistema é suficiente, entretanto sugere-se que o mercado faça um estudo para

ReLAInEP - Revista Latino-America de Inovação e Engenharia de Produção, Curitiba, PR, Brasil, v. 3, n. 4, p. 223-234, 2015. 


\section{ReLAInEP}

definir as melhores rotas de entrega de compras aos clientes, para que as mesmas cheguem mais rapidamente e com o menor custo possível para o mercado.

\section{REFERÊNCIAS}

BALLOU, R. H. Gerenciamento da Cadeia de Suprimentos: planejamento, organização e logística empresarial. Porto Alegre: Bookman, 2006.

FLEURY, P. F., WANKE, P., FIGUEIREDO, K. F. Logística empresarial: a perspectiva brasileira. 1 ed. 16. São Paulo: Atlas, 2013.

MARQUES, V. Utilizando o TMS (“Transporte Management System") para uma gestão eficaz de transportes, 2002.

NAZÁRIO, P. A importância de Sistemas de Informação para a Competitividade Logística. 2008.

OLIVEIRA, N. Aumento do poder de compra promove expansão do volume de vendas em mercados. Empresa Brasil de Comunicação - EBC, Brasília, DF. 15 de abril de 2014. Economia. Disponível em: <http://www.ebc.com.br/noticias/economia/2014/04/aumento-dopoder-de-compra-promove-expansao-do-volume-de-vendas-em> Acesso em: 25 de abril de 2014.

PEOPLESOFT. EnterpriseOne 8.9, gerenciamento de pedidos de vendas PeopleBook.2007. Disponível em <docs.oracle.com/cd/E12293_01/jded/acrobat/SCM89PSO0309.pdf> Acesso em 25 de abril de 2014.

REIS, C. E. A importância da gestão da cadeia logística para a melhoria do nível de serviços prestados. 75 f. Trabalho de Conclusão de Curso (Graduação em Administração) Universidade Federal do Rio Grande do Sul, Porto Alegre, 2007.

ReLAInEP - Revista Latino-America de Inovação e Engenharia de Produção, Curitiba, PR, Brasil, v. 3, n. 4, p. 223-234, 2015. 